The mechanisms associated with such clinical benefit should be elucidated in future research.

References:

[1] Prevoo et al. Arthritis Rheum 1995;38:44-8.

[2] Fransen \& van Riel. Clin Exp Rheumatol 2005;23:S93-9.

[3] van Gestel et al. Arthritis Rheum 1998;41:1845-50.

[4] Alten et al. Clin Rheumatol (2019) 38: 1413.

Acknowledgments: Yusuf Patel

Srinivasan Venkatachalam

James Maxwell

Usman Farooqui

Kevin Pollock

Disclosure of Interests: Sadie Henning Shareholder of: Sadie Henning is a shareholder for Bristol-Myers Squibb Pharmaceuticals Ltd., Employee of: Sadie Henning is employed by Bristol-Myers Squibb Pharmaceuticals Ltd., Lara Groves Grant/ research support from: Lara Groves is an employee of Health Economics and Outcomes Research Ltd., Cardiff, UK, who received fees from Bristol-Myers Squibb Pharmaceuticals Ltd in relation to this study., Michael Hurst Grant/research support from: Michael Hurst is an employee of Health Economics and Outcomes Research Ltd., Cardiff, UK, who received fees from Bristol-Myers Squibb Pharmaceuticals Ltd in relation to this study., Daniel Sugrue Grant/research support from: Daniel Sugrue is an employee of Health Economics and Outcomes Research Ltd., Cardiff, UK, who received fees from Bristol-Myers Squibb Pharmaceuticals Ltd in relation to this study., Jason Gordon Grant/research support from: Jason Gordon is an employee of Health Economics and Outcomes Research Ltd., Cardiff, UK, who received fees from Bristol-Myers Squibb Pharmaceuticals Ltd in relation to this study., Ernest Choy Grant/ research support from: Amgen, Bio-Cancer, Chugai Pharma, Ferring Pharmaceuticals, Novimmune, Pfizer, Roche, UCB, Consultant of: AbbVie, Amgen, AstraZeneca, Biogen, Boehringer Ingelheim, Bristol-Myers Squibb, Celgene, Chelsea Therapeutics, Chugai Pharma, Daiichi Sankyo, Eli Lilly, Ferring Pharmaceuticals, GlaxoSmithKline, Hospita, Ionis, Janssen, Jazz Pharmaceuticals, Medlmmune, Merck Sharp \& Dohme, Merrimack Pharmaceutical, Napp, Novartis, Novimmune, ObsEva, Pfizer, R-Pharm, Regeneron Pharmaceuticals, Inc., Roche, SynAct Pharma, Sanofi Genzyme, Tonix, UCB, Speakers bureau: Amgen, Boehringer Ingelheim, Bristol-Myers Squibb, Chugai Pharma, Eli Lilly, Hospira, Merck Sharp \& Dohme, Novartis, Pfizer, Regeneron Pharmaceuticals, Inc., Roche, Sanofi-Aventis, UCB

DOI: 10.1136/annrheumdis-2020-eular.1069

\section{AB0296 1 EFFECTIVENESS OF CERTOLIZUMAB IN 506 PATIENTS WITH RHEUMATOID ARTHRITIS, PSORIATIC ARTHRITIS, AND SPONDYLOARTHRITIS FROM THE APULIAN REGISTRY BIOPURE.}

F. Iannone ${ }^{1}$, N. Maruotti ${ }^{2}$, A. Semeraro ${ }^{3}$, R. Bucci ${ }^{4}$, G. Carlino ${ }^{5}$, L. Santo ${ }^{6}$ L. Quarta ${ }^{7}$, C. Zuccaro ${ }^{8}$, G. Santacesaria ${ }^{9}$, M. Fornaro ${ }^{1}$, F. P. Cantatore ${ }^{2}$. ${ }^{1}$ Rheumatology Unit, Department of Emergency and Organ Transplantations, University of Bari "Aldo Moro," Bari, Italy; ${ }^{2}$ Rheumatology Unit, University of Foggia, Foggia, Italy; ${ }^{3}$ Rheumatology Unit, ASL Taranto, Martina Franca, Italy; ${ }^{4}$ Rheumatology Hospital Unit, AOU Foggia, Foggia, Italy; ${ }^{5}$ Rheumatology Service, ASL LE - DSS Casarano-Gallipoli (LE), Casarano, Italy; ${ }^{6}$ Rheumatology Unit, ASL BT, Barletta, Italy; ${ }^{7}$ Rheumatology Unit, "Vito Fazzi” Hospital, Lecce, Lecce, Italy; ${ }^{8}$ Rheumatology Clinic, "Antonio Perrino" Hospital, Brindisi, Brindisi, Italy; ${ }^{9}$ Rheumatology Service, ASL LE, Lecce, Italy

Background: Little is known about effectiveness of certolizumab (CTZ) in clinical practice, especially in patients with inadequate response to prior biologics. Objectives: To estimate the survival rate of CTZ in RA, PsA or SpA cohorts from the registry BIOPURE. Secondary endpoint was the changes of clinical outcomes from baseline at 6 and 12 months for each disease.

Methods: We analyzed longitudinal data of consecutive patients, affected with RA, PsA or SpA starting a treatment with CTZ recorded into the web-based Apulian registry BIOPURE. Demographic and disease related characteristics were collected at baseline, 6 and 12 months. Drug survival was evaluated by Kaplan-Meier life table analysis. Estimates hazard ratios (HRs, 95\% confidence intervals $(\mathrm{Cl})$ ) of drug discontinuation adjusted for patient's demographics, disease characteristics and prior biologic treatments were computed by Cox-regression models. Differences of DAS28, DAPSA and BASDAI among baseline, 6 and 12 months were estimated by T-test. Results: 506 patients were included in this analysis (table 1). Global mean survival time $(95 \% \mathrm{Cl})$ was $58(52-64)$ months. Drug survival rate was significantly higher in RA (71.1\%) than in PsA (63.5\%, p=0.001), while SpA showed 67.5\% (Figure 1). Naïve-CTZ patients showed higher survival rates than biologic-inadequate responder (Bio-IR) patients in PsA (naïve $78.4 \%$ vs $56.9 \%, p=0.02$ ), but not in RA (76.9\% vs $64.1 \%, p=0.08)$, or $\mathrm{SpA}(73.7 \%$ vs $64.8 \%, \mathrm{p}=0.84)$. The only weak predictor of drug discontinuation was age at baseline for SpA patients (HR 1.04 (95\% $\mathrm{Cl}: 1.005-1.007) \mathrm{p}=0.02$ ) (Figure 1). No baseline covariate, including sex, cDMARDs co-therapy and biologic-naïve status, was found to be associated with CTZ discontinuation for RA and PsA cohorts. A significant improvement of clinical outcomes from baseline was seen at 6 and 12 months, regardless prior biologic therapies. In RA DAS28 dropped from $3.95 \pm 1.5$ to $2.77 \pm 1.3$ at 6 months $(p=0.0001)$ and 2.55 \pm 1.3 at 12 months $(p=0.0001)$. In PsA DAPSA decreased from $19.1 \pm 10$ to 10.8 \pm 8 at 6 months $(p=0.0001)$ and $9.6 \pm 7$ at 12 months $(p=0.0001)$. In SpA DAS28 reduced from $3.66 \pm 1.4$ to $2.85 \pm 1.3$ at 6 months $(p=0.0001)$ and $2.55 \pm 1.1$ at 12 months $(p=0.0001)$. Additionally, in SpA BASDAI dropped from $5.3 \pm 1.6$ to $3.8 \pm 2.3$ at 6 months $(p=0.0001)$ and $2.8 \pm 1.8$ at 12 months $(p=0.0001)$.

Conclusion: In real-life settings CTZ has shown a good effectiveness also in Bio-IR patients. Unlike other TNF-inhibitors, the clinical response and the survival rate were also meaningful in RA patients.

Table:

\begin{tabular}{lccc}
\hline & $\begin{array}{c}\text { RA } \\
(n r .180)\end{array}$ & $\begin{array}{c}\text { PsA } \\
(\text { nr.189) }\end{array}$ & $\begin{array}{c}\text { SpA } \\
(\mathrm{nr} .137)\end{array}$ \\
\hline Age (mean \pm SD) & $54.5 \pm 12$ & $50.6 \pm 12$ & $52.0 \pm 11$ \\
Female & $82.9 \%$ & $74.6 \%$ & $56.3 \%$ \\
BMI (mean) & $25.9 \pm 5$ & $28.4 \pm 5$ & $26.7 \pm 5$ \\
Dis Durat months (mean \pm SD) & $46 \pm 14$ & $106 \pm 82$ & $97 \pm 92$ \\
Naive & $53.9 \%$ & $32.8 \%$ & $28.5 \%$ \\
Prior biologics & $52.9 \%$ & $75.0 \%$ & $71.1 \%$ \\
Glucocorticoids & $55.9 \%$ & $39.7 \%$ & $39.4 \%$ \\
DMARDs & $72.4 \%$ & $52.4 \%$ & $43.8 \%$ \\
DAS28 (mean \pm SD) & $4.8 \pm 1.5$ & $3.6 \pm 1.2$ & $3.7 \pm 1.3$ \\
BASDAl (mean \pm SD) & & & $5.2 \pm 2$ \\
DAPSA (mean \pm SD) & $1.2 \pm 0.7$ & $19.7 \pm 10$ & \\
HAQ (mean \pm SD) & $72.4 \%$ & & \\
RF/ACPA + & & & \\
\hline
\end{tabular}
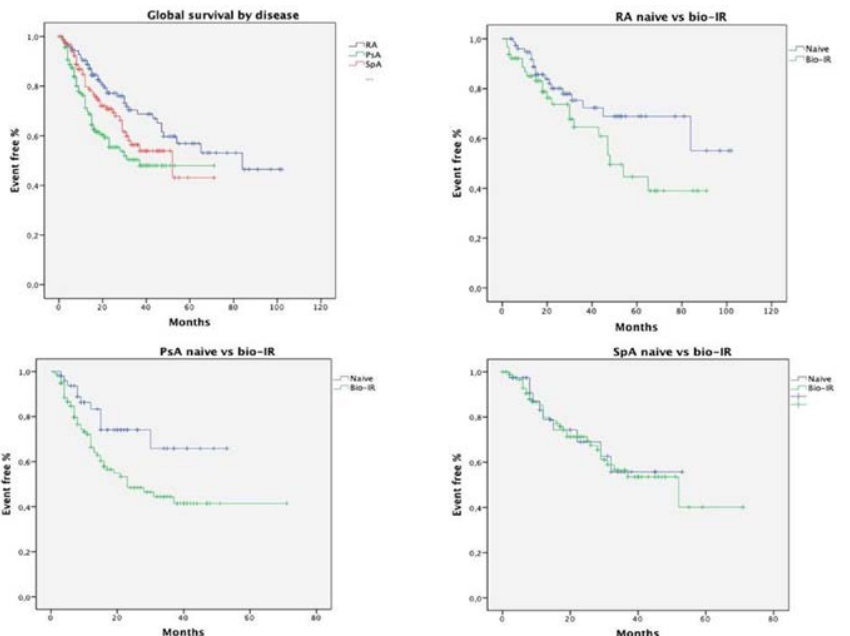

Disclosure of Interests: Florenzo lannone Consultant of: Speaker and consulting fees from AbbVie, Eli Lilly, Novartis, Pfizer, Roche, Sanofi, UCB, MSD, Speakers bureau: Speaker and consulting fees from AbbVie, Eli Lilly, Novartis, Pfizer, Roche Sanofi, UCB, MSD, Nicola Maruotti Speakers bureau: Pfizer, Angelo Semeraro Speakers bureau: Sanofi, Roche, AbbVie, BMS, MSD, Novartis, Romano Bucc Speakers bureau: Pfizer, Sanofi, MSD, BMS, Giorgio Carlino Speakers bureau: Pfizer, Janssen, AbbVie, MSD, BMS., Leonardo Santo Consultant of: AbbVie, MSD, Novartis UCB outside this work, Speakers bureau: AbbVie, MSD, Novartis UCB outside this work, Laura Quarta: None declared, Carmelo Zuccaro Consultant of: MSD, AbbVie Novartis, Pfizer, Janssen outside this work, Speakers bureau: MSD, AbbVie, Novartis, Pfizer, Janssen outside this work, Giuseppina Santacesaria: None declared, Marco Fornaro: None declared, Francesco Paolo Cantatore: None declared DOI: 10.1136/annrheumdis-2020-eular.5899

\section{AB0297 THE LONG-TERM OBSERVATION OF PATIENTS WITH RHEUMATOID ARTHRITIS WHO ACHIEVED A BIO FREE CONDITION WITH ADALIMUMAB.}

S. Ito ${ }^{1}$, S. Sakai ${ }^{1}$, Y. Kurosawa ${ }^{1}$, D. Kobayashi ${ }^{2}$, R. Okabayashi ${ }^{1}$, A. Abe ${ }^{1}$, H. Otani ${ }^{1}$, K. Nakazono ${ }^{1}$, A. Murasawa ${ }^{1}$, I. Narita ${ }^{2}$, H. Ishikawa ${ }^{1} .{ }^{1}$ Department of Rheumatology, Niigata Rheumatic Center, Shibata, Japan; ${ }^{2}$ Division of Clinical Nephrology and Rheumatology Niigata University Graduate School of Medical and Dental Sciences, Niigata, Japan

Background: Biological disease-modifying antirheumatic drugs (bDMARDs) caused a paradigm shift in the treatment of rheumatoid arthritis (RA). However their high cost is a burden for patients and the national medical economy. Objectives: To analyze the long-term outcomes of patients with RA who achieved a bio-free condition (BF) with adalimumab (ADA). 
Methods: We followed 25 patients (male 6, female 19) who discontinued ADA with clinical remission (CR), and one female with a low disease activity (LDA), over 19.4 \pm 7.8 months of ADA treatment ${ }^{1)}$. At the introduction of ADA, the average age was $51.2 \pm 11.9$ years old, and the average disease duration was $45.1 \pm 48.4$ months. The disease activity measured by disease activity score based on C-reactive protein (DAS28-CRP) was defined as follows: CR, <2.3; LDA, 2.3 - 2.7; moderate DA, $2.7-4.1$; and high DA, > 4.1, since the DAS28-CRP tends to be lower than the DAS28-based on the erythrocyte sedimentation rate in Japanese patients ${ }^{2}$.

Results: We lost one patient with a transfer to another hospital. Four patients re-started ADA due to flare (DAS28-CRP>2.7) but achieved $C R$ (in BF) again with the intensification of the treatment (dose increase or initiation of prednisolone [PSL] and/or conventional synthetic [cs] DMARDs such as tacrolimus or iguratimode). The DAS28-CRP significantly decreased from $3.45 \pm 1.32$ at base line $(B L)$ to $1.55 \pm 0.41(p<0.0001)$ at BF. It remained $1.59 \pm 0.59(n=25)$ at 24 months after $B F, 1.56 \pm 0.39(n=20)$ at 48 months, $1.8 \pm 0.7(n=11)$ at 60 months. At the last observation, every patient remained in $\mathrm{CR}$ up to 84 months ( $\mathrm{n}=2$, Figure 1). The modified health assessment questionnaire score significantly decreased from $0.42 \pm 0.46(B L, n=19)$ to $0.02 \pm 0.05(p<0.002)$ at BF. It remained $0.03 \pm 0.07(n=19)$ at 24 months and $0.06 \pm 0.14(n=14)$ at 48 months, $0.04 \pm 0.08$ at 60 months $(n=9)$. The PSL dose $(\mathrm{mg} /$ day) decreased from $3.2 \pm 3.3$ $(B L)$ to $2.2 \pm 2.8$ at BF and $2.04 \pm 2.13(n=25)$ at 24 months, $1.73 \pm 1.9(n=20)$ at 48 months, and $1.6 \pm 2.3(n=11)$ at 60 months, but there were no significant changes. The methotrexate (MTX) dose (mg/week) increased from $10.1 \pm 2.9(\mathrm{BL})$ to $10.6 \pm 2.6(\mathrm{p}<$ $0.78)$ at $B F, 10.4 \pm 3.3(n=25)$ at 24 months, $10.7 \pm 3.4(n=20)$ at 48 months, $10.4 \pm 3.1$ at 60 months (not significant). The number of csDMARDs significantly increased from $0.8 \pm 0.6(B L)$ to $1.3 \pm 0.9(p<0.001$, at $B F), 2.56 \pm 0.94(n=25)$ at 24 months, $1.6 \pm 1.01$ $(n=20)$ at 48 mnths, and $1.6 \pm 2.3$ at 60 months $(n=11$, Figure 2$)$.

Conclusion: BF can be sustained with an adequate dose of MTX and combination of csDMARDs.

References:

[1] Ito $S$, et al. An analysis of the biological disease-modifying antirheumatic drug-free condition of adalimumab-treated rheumatoid arthritis patients. Intern Med 58: 511-519, 2019

[2] Inoue E, et al. Comparison of Disease Activity Score (DAS)28-erythrocyte sedimentation rate and DAS28- C-reactive protein threshold values. Ann Rheum Dis. 66:407-409, 2007.

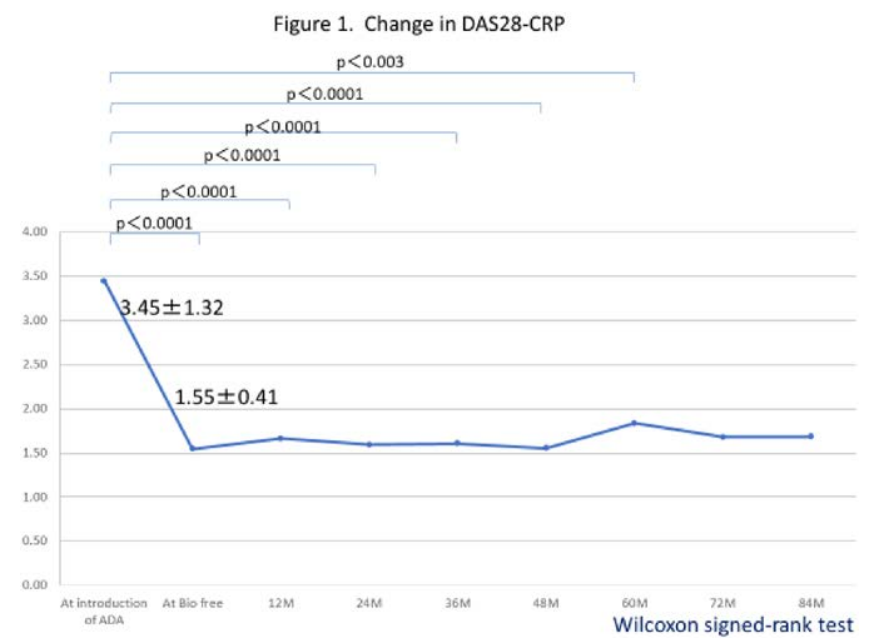

Figure 2. The number of csDMARDs

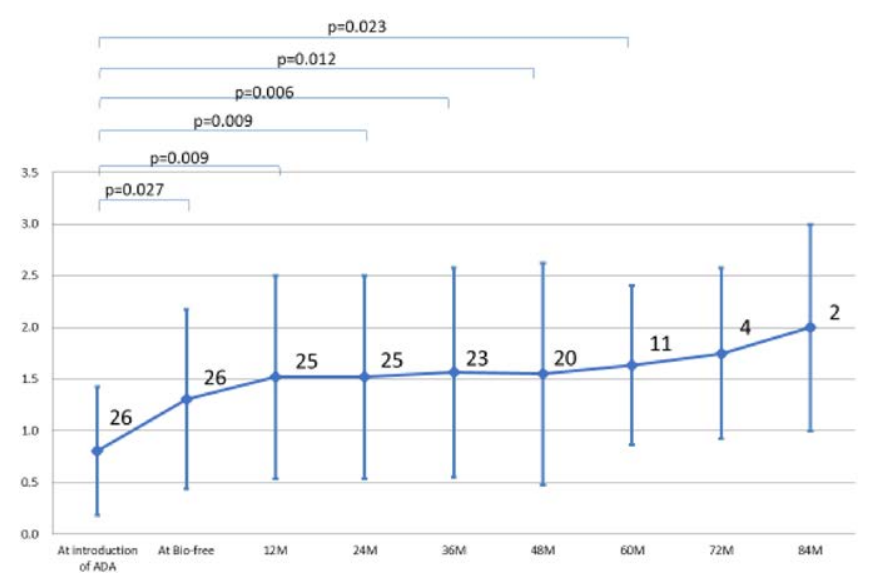

Disclosure of Interests: Satoshi Ito Speakers bureau: Abbvie,Eisai, Shunsuke sakai: None declared, Yoichi Kurosawa: None declared, Daisuke Kobayashi: None declared, Ryo Okabayashi: None declared, Asami Abe: None declared, Hiroshi Otani: None declared, Kiyoshi Nakazono: None declared, Akira Murasawa: None declared, Ichiei Narita: None declared, Hajime Ishikawa: None declared

DOI: 10.1136/annrheumdis-2020-eular.2406

\begin{tabular}{l|l}
\hline AB0298 & LONG-TERM SUPPRESSION OF RAPID RADIOGRAPHIC \\
PROGRESSION AFTER DISCONTINUATION/REDUCTION \\
OF SHORT-TERM BIOLOGIC THERAPY IN PATIENTS \\
WITH EARLY DESTRUCTIVE RHEUMATOID ARTHRITIS \\
ACCOMPANIED WITH EXTENSIVE BONE MARROW \\
EDEMA.
\end{tabular}

K. Katayama ${ }^{1}$, T. Okubo ${ }^{2}$, T. Sato ${ }^{1}$, R. Fukai ${ }^{3}$, M. Yuichi ${ }^{4}$, K. Yujiro ${ }^{5}$, H. Ito ${ }^{6}$. ${ }^{1}$ Katayama Orthopedic Rheumatology Clinic, Rheumatology, Asahikawa, Japan; ${ }^{2}$ Katayama Orthopedic Rheumatology Clinic, Radiology, Asahikawa, Japan; ${ }^{3}$ Fukai Pharmacy, Asahikawa, Japan; ${ }^{4}$ Asahikawa Medical University, Asahikawa, Japan; ${ }^{5}$ Sapporo Rheumatogy and Immunology Clinic, Sapporo, Japan; ${ }^{6}$ Asahikawa Medical University, Orthopedic Surgery, Asahikawa, Japan

Background: We reported that short-term (3 or 6 months) treatment with biologics (BIO) group compared with conventional synthetic non-biological disease-modifying anti rheumatic drug (csDMARDs) enhanced group is more effective in the reducing bone marrow edema $(B E)$ and improving structura remission in early destructive $\mathrm{RA}$ accompanied with extensive hand $\mathrm{BM}$ despite csDMARDs therapy (1)

Objectives: Purpose of this extended study is to investigate whether suppression of RRP will maintain after the discontinuation/reduction of short term biological treatment during over 1 year. Clinical registration number; (UMIN-CTR 000013614)(Figure 1)

Methods: RA disease activity was evaluated by DAS28-ESR after BIO withdrawal/reduction at 12 months. Bone destruction was determined by modified total Sharp scoring (mTSS) using by conventional radiography expressed as yearly progression of mTSS ( $\mathrm{mTTSS} / \mathrm{y})$ at 12 months. Sta tistical analysis were performed by t-test or Wilcoxon rank sum test using SAS .13 .2 software

Results: Fourteen out of 23 patients in BIO group achieved improvement of BM (>70\% improvement of baseline BE). Three patient continued BIO. Among 11 patient started to discontinuation/reduction of $\mathrm{BIO}, 7$ patients were successful for discontinuation of BIO. Four patients flared (Table 1). Mean DAS28-ESR, mean $\Delta \mathrm{mTSS} / \mathrm{y}$ at 0,12 months after discontinuation in 7 patients were $1.77,2.02$ and $-0.66,-0.44$, respectively (no significant difference between values in 0 and12 month). In contrast, those in 4 flared patients were 1.91, 4.08 and 0, 1.83, respectively (significant difference). Finally, to resolve baseline prognostic factors for improvement of $\mathrm{BE}$ for biological treatment, we compared baseline data between 14 BE improved and 9 BE unimproved RA patients. Low DAS28-ESR at 3 or 6 month $(P<0.001)$ are indicated for significant prognostic factor for improvement of $B E$, although Low DAS28-ESR at baseline $(P=0.07)$ may associate improvement of $B E$.

Table1. Summary of 1 year clinical data in 11 patients treated in BIO discontinuation/ reduction after improvement of BE by short-term treatment of BIO.

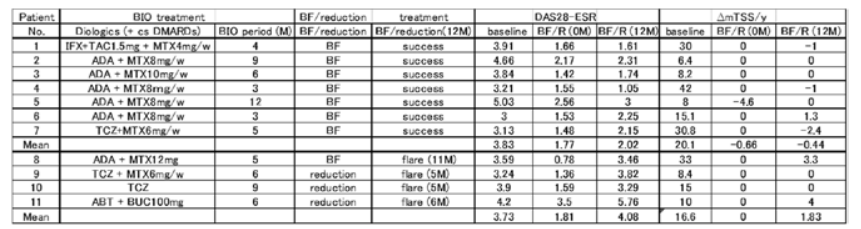

Conclusion: Results of this study indicated suppression of RRP will maintain during over 1 year after the discontinuation of short term biologica treatment in some patients. We recommend that a short-term treatment with biologics for early RA patients, who are resistant to non-bio DMARDs therapy and at high risk to transit to RRP, will be an effective and economical treatment strategy.

References:

[1] K. Katayama, T. Okubo, S. Sato et al. Prevention of extensive bone marrow edema and consequent rapid radiographic progression by short term usage of biologics in DMARDs resistant patients with early destructive rheumatoid arthritis. EULAR meeting. FRI 0124(2018). 